\title{
Medios publicitarios que influyen en el consumidor a la hora de adquirir un producto o servicio
}

\section{Advertising media that influence the consumer at the time of acquire a product or service}

\author{
Jorge Guido Sotomayor Pereira ${ }^{1 *}$, Luis Felipe Brito Gaona ${ }^{1}$ y Mayra Alejandra Tenesaca Fajardo \\ ${ }^{1}$ Universidad Técnica de Machala \\ *jsotomayor@utmachala.edu.ec
}

DOI: https://doi.org/10.26871/killkana_social.v2i3.347

\begin{abstract}
Resumen
Actualmente la comunicación y el acceso a la información son ilimitados. El desarrollo de la tecnología y la aparición del internet han mejorado nuestros estilos de vida y han contribuido en el sector empresarial, sobre todo en el desarrollo de estrategias comunicacionales para mantenerse cerca de su mercado. Los medios de comunicación no solo transmiten una idea o mensaje a un receptor, también llegan a persuadir el contenido y la idea general del mensaje, pues se adaptan a las necesidades del mercado. Las empresas lo eligen y personalizan dichos medios en contenidos didácticos y persuasivos que estimulen su decisión de compra o preferencia por algún producto o servicio. El presente artículo tiene como objetivo determinar los medios publicitarios que influyen en el consumidor. Para ello se ha elaborado una investigación cuantitativa destinada a recabar información sobre los medios que influyen en la decisión de compra de los habitantes en la ciudad de Machala. La presentación de los resultados se establece mediante la división de los medios convencionales y no convencionales. En este sentido la utilización de medios publicitarios es un estudio más minucioso, debido a que la población no solo se fija en la idea transmitida, sino también la forma en que está expuesta, cómo la observa y el medio donde la observó. Todos estos elementos ayudan a estimular el mensaje en la memoria del receptor y provocar una acción de compra.
\end{abstract}

Palabras clave: medios publicitarios, medios convencionales, medios no convencionales, sistema de representación, decisión de compra.

\begin{abstract}
Actually the communication and access to information are unlimited. The development of technology and the emergence of the Internet have improved our lifestyles and have contributed in the business sector, especially in the development of communication strategies to stay close to its market. The media not only transmit an idea or message to a receiver, but they also persuade the content and the general idea of the message, because they adapt to the needs of the market. The companies choose and personalize these means in didactic and persuasive contents that stimulate their choice of purchase or preference for some product or service. This article aims to determine the advertising media that influence the consumer. To this end, it has developed a quantitative research aimed at gathering information on the means that influence the decision of purchase of the inhabitants in the city of Machala. The presentation of results is established through the division of conventional and non-conventional media. In this sense the utilization of advertising media is a more detailed study, because the population not only fixes on the idea transmitted, but also the form in which it is exposed, how it observes it and the environment where it observed it. All these elements help to stimulate the message in the receiver's memory and trigger a purchase action.
\end{abstract}

Key words: Advertising media, conventional media, non-conventional media, representation system, purchase decision.

\section{Introducción}

La publicidad es definida como la forma pagada de presentación y promoción no personal de ideas, bienes o servicios, por un patrocinador identificado (Kotler y Armstrong, 2011); y se constituye como una poderosa técnica del marketing que contribuye a la comunicación y forma de promocionar los productos o servicios que una empresa oferta en el mercado. Esta actividad publicitaria se ha desarrollado a lo largo del tiempo. Russell, Lane y Whitehill en su libro Publicidad (2005) indican que en la era del pre marketing, la comunicación se realizaba rústicamente mediante diálogos. Más adelante, con la aparición de la 
imprenta se utilizó la cartelera, que son letreros impresos ubicados en la parte externa de las tiendas; al mismo tiempo se intensificó el uso del periódico y continuamente la radiodifusión. Posteriormente, los publicistas se dedicaron a estudiar al cliente, segmentos y datos generales que les permitieron desarrollar la comunicación interactiva para llegar a ellos con información personalizada en medios controlados por los consumidores (Russell y cols., 2005)

Los medios publicitarios son los canales que las empresas utilizan para enviar publicidad al consumidor. Estos pueden ser de tipo convencional si el mensaje es transmitido en medios de comunicación masiva tales como: radio, prensa y televisión; y no convencionales conocidos como below the line, que pueden ser actos de patrocinio, marketing directo, juegos promocionales, etc. (Garcia Uoeda, 2011). Además con el desarrollo de las Tics, Tecnologías de información y comunicación y el comercio electrónico se ha intensificado los medios para llegar al consumidor, utilizándolas para llevar un mensaje de forma rápida y efectiva (Rivera y Rodríguez, 2011), siendo el internet el medio que más ingresos recibirá en comparación con la radio como medio más tradicional y de segunda audiencia cuantitativamente mayoritaria (Molina, 2008).

La presente investigación tiene como propósito determinar el impacto que genera los medios publicitarios en los consumidores, para tal efecto se realizará una revisión bibliográfica con respecto al tema de estudio. El levantamiento de la información se realizará tomando en consideración la muestra poblacional obtenida y utilizando a la encuesta como instrumento de investigación; todo esto realizado en un tiempo determinado. La recopilación y tabulación de los resultados obtenidos son analizados que permiten establecer conclusiones aplicadas al tema investigado, recordando que sea cualquier medio publicitario que se utilice, el contenido que se presente debe atraer, mantener y conseguir un cliente nuevo o conservar el mismo en todo el proceso que realiza la decisión de compra de algún producto. (Valencia Medranda, Palacios Bauz, Cedeño Pinargote, Collins Ventura, y de Ingeniería en Marketing, 2015).

\section{Marco Teórico}

\subsection{Publicidad y la comunicación a la hora de adquirir un producto o servicio}

En 1978 la UNESCO, órgano creado por la Organización de las Naciones Unidas, expresa que la publicidad es esencialmente una actividad de comunicación, que forma parte del proceso y del sistema de comunicación y que apunta a promover la venta de un artículo, producto o servicio; a fomentar una idea o a lograr cualquier otro efecto que desee conseguir el anunciante. (Degrado, 2005)

Según el Diccionario de la Real Academia Española, DRAE, define a la publicidad como el "conjunto de medios que se emplean para divulgar o extender la noticia de las cosas o de los hechos". También incluye a la "divulgación de noticias o anuncios de carácter comercial para atraer a posibles compradores, espectadores, usuarios, etc." (Española, s.f.).

Particularmente, Meffert (2012) indica que la publicidad se enmarca en el contexto de promoción y se define como un proceso de comunicación masiva diseñada para cambiar la actitud y comportamiento de sus receptores (Valencia Medranda y cols., 2015)

Pero la definición más conocida y utilizada por expertos para definir a la publicidad es establecida por Kotler y Armstrong (2011) como "cualquier forma pagada de presentación y promoción no personal de ideas, bienes o servicios, por un patrocinador identificado" (pág. 461).

Por otro lado tenemos a la comunicación, definida por Chiavenato (2007) como "el intercambio de información entre personas. Significa volver común un mensaje o una información. Constituye uno de los procesos fundamentales de la experiencia humana y la organización social" (pág. 110). También agrega que requiere de un código para enviar el mensaje, por un determinado canal a un receptor.

Según, Stanton, Etzel y Walker (2007) indican que "es la transmisión verbal o no verbal de información entre alguien que quiere expresar una idea y quien espera captarla o se espera que la capte" (pág. 511); requiriendo de cuatro elementos, como son: el mensaje, fuente del mensaje, un canal de comunicación y un receptor

El Diccionario de la Real Academia Española, indica diversas definiciones a este término, pero acerándose a temas de marketing y publicidad y al tema investigado se define como "acción y efecto de comunicar o comunicarse" a través de la "transmisión de señales mediante un código común al emisor y al receptor” (DRAE).

Comunicación es transmitir señales mediante un código común del emisor y el receptor. Se entiende por comunicación el intercambio de significados entre personas mediante un sistema de símbolos; por un lado, dar a conocer y por otro, aprender. (Degrado, 2005)

La publicidad es una forma de comunicación y esto se justifica desde el punto en que la publicidad emite un mensaje y existe un receptor que asimila la información que recibe. (Degrado, 2005)

Las herramientas de comunicación ayudan a crear imágenes poderosas y un sentido de credibilidad, confianza y tranquilidad. Según Candido y Viera (2003) indica que entender el comportamiento de los clientes y crear un canal de comunicación por parte del prestador de servicios es una de las acciones que compete al marketing. (Mondo y Costa, 2011)

Según las definiciones de estos dos términos, se observa la relación que existe entre ellos, la publicidad encargada de transmitir una idea, un bien o servicio utilizando un medio de comunicación que le permita llevar esa información. En el aspecto empresarial, el emisor es el anunciante, la empresa que quiere informar u ofrecer productos a un receptor, quienes son los clientes, públicos objetivos o un segmento de mercado específico, que son persuadidos por 
un mensaje diseñado estratégicamente a través de un medio de comunicación elegido.

\subsection{El medio publicitario y sus tipos}

Se entiende como medio publicitario a cualquier espacio donde se pueda ubicar un mensaje de la empresa -sea cual sea la forma en que se haya elaborado- (Rodriguez del Bosque, Suárez Vázquez, y García de los Salmones, 2008). Utiliza distintos canales de comunicación que le permita transmitir un mensaje publicitario (Valdiva Garcia, 2015).

El campo publicitario ha tenido una gran evolución debido a las revoluciones tecnológicas presentadas en el entorno debido a factores como: anunciantes, agencias, proveedores y sobre todo los medios de comunicación. (Cevallos, Limonta, y Dueñas, 2017)

Los medios, actividades o canales que se utiliza en la publicidad para anunciar productos o servicios se dividen tradicionalmente en medios convencionales o mass media y medios no convencionales o alternativos.

La publicidad realizada en medios convencionales es:

- Prensa: diarios, dominicales, revistas de información general, femeninas, decoración, etc.

- Radio: en cadenas y emisoras

- Televisión: televisión por satélite, cable

- Cine: salas comerciales y cine-clubes

- Exterior: vallas, cabinas telefónicas, transporte públicos, áreas, marquesinas, estadios deportivos

- A través de las nuevas tecnologías: internet. (Valdiva Garcia, 2015)

La publicidad no convencional consiste en un conjunto de acciones que se realiza a través de los medios no convencionales y que se plantean como alternativa o complementos a la acción publicitaria en los mass media.

- Publicidad directa: mailing, buzoneo, correo, telemarketing, etc.

- Publicidad en el lugar de venta: expositores, displays, etc (Valdiva Garcia, 2015).

La empresa que requiera seleccionar un medio o conjuntos de medios y soportes para llevar a cabo la campaña publicitaria en función de los siguientes factores:

- Presupuesto real disponible

- Objetivos perseguidos por la campaña

- Tipo de producto

- Creatividad desarrollada

- Alcance óptimo de cada medio

- Público objetivo

- Tarifas y posibilidad de negociación que ofrezca los medios

- Estacionalidad en distribución de los medios y sus diferentes soportes

- Uso que haga la competencia (Valdiva Garcia, 2015)

El formato audiovisual es el medio que define el siglo XX y el siglo XXI. Como indica McQuail en 1998, la televisión es el medio que cambió el mundo de la comunicación. La visión de lejos, o televisión, permitía que el espectador pudiera ver los mensajes publicitarios con imagen y sonido, ocasionando que se impregnara mayormente en la memoria, y hasta finales del siglo XX se exponía que "todo aquello que no sale en televisión no existe" (Gema, Casado, y Valladolid, 2012).

Así mismo, la evolución de los formatos publicitarios en internet han tenido un largo proceso, desde enlaces de patrocinio, banner estáticos posteriormente con movimientos, interstitial, y layers, llegando a los spots publicitarias, donde los estrategas comparten el mensaje en distintos medios (tv e internet-youtube) (Madinabeitia, 2010). Desde ese momento hasta la actualidad, el mensaje publicitario audiovisual alcanza gran impacto y éxito, sea por televisión o por las nuevas tecnologías. Lo difícil es lograr grandes índices de notoriedad considerables puesto a que el espectador encuentra gran cantidad de posibilidades de elección (Gema y cols., 2012)

Cada vez aparecen nuevos medios que ofrecen mejores posibilidades para adaptarse y dirigirse a un mercado, siendo compleja su selección por el alto número de soportes publicitarios existentes. (Natalia, 2014) La selección y utilización de los medios publicitarios cada vez se hace más meditada, pues de acuerdo a la actividad comercial que se dedica una empresa y los segmentos de mercado que maneja y quiere alcanzar la selección de estrategias de medios se precisa

Las estrategias de medios actuales integran diferentes técnicas, como son: la organización de eventos, creación y difusión de noticias en los diferentes medios de comunicación, contratación de publirreportajes y otros formatos publicitarios tradicionales como el spot de televisión o los anuncios en prensa especializada y aprovechamiento de los canales que ofrecen las herramientas digitales como las redes sociales o internet. (Galmés-cerezo y Arjona-martín, 2014).

El acceso de la audiencia al internet no cesa de crecer y la segmentación no tiene límites.(Martín-Guart y Fernández Cavia, 2014). Es evidente que en una época de revolución tecnológica y porque no decir publicitaria, los forma de hacer marketing y publicidad se transforman constantemente, por parte de los anunciantes (marcas y empresas), consumidores, medios (convencionales y tecnológicos) y el internet quien suma un gran peso en el proceso de comunicación publicitaria, donde el consumidor puede acceder a la información en cualquier momento y lugar.

\section{Metodología}

La presente investigación se realizó con el objetivo de determinar los medios publicitarios que influyen en el consumidor a la hora de elegir un producto o servicio mediante el desarrollo y ejecución de una investigación de mercado de tipo cuantitativa.

La investigación fue aplicada en la ciudad de Machala a hombres y mujeres, estudiantes con educación superior, y personas económicamente activa a partir de un rango de edad de 15 a 70 años, considerando la proyección 
poblacional de la ciudad según el SENPLADES (Secretaria Nacional de Planificación y Desarrollo) al año 2016, siendo 276.669 habitantes, cuyo número se destinó al cálculo de la muestra con el $95 \%$ de nivel de confianza y el $5 \%$ de margen de error, obteniendo una muestra de 384 personas.

El instrumento de investigación aplicado es la encuesta, misma que considera una serie de preguntas cerradas y de opción múltiple. Previo al levantamiento de la información se realizó una prueba piloto que permitió reducir el grado de incertidumbre al momento de ejecutar la encuesta real a la muestra seleccionada.

El levantamiento de la información tuvo una duración de dos semanas, proceso que al finalizar se procedió a analizar, tabular y representar gráficamente para posteriormente presentar los resultados detalladamente que aporta a la investigación y la toma decisiones de las empresas.

\section{Resultados}

De acuerdo a la investigación realizada se obtuvo la siguiente información:

Para recordar una publicidad, las personas encuestadas indicaron según lo expuesto en la figura 1 que el $44 \%$ de ellas memorizan lo que ve, un $23 \%$ toma una foto o graba un video y el $11 \%$ repite una y otra vez la información.

Esto significa que el tipo de publicidad, representada en la figura 2, más fácil a recordar es la publicidad visual en el $50 \%, 23 \%$ dinámica y el $23 \%$ hablada.

Figura 1. Actividad que realiza para recordar publicidad

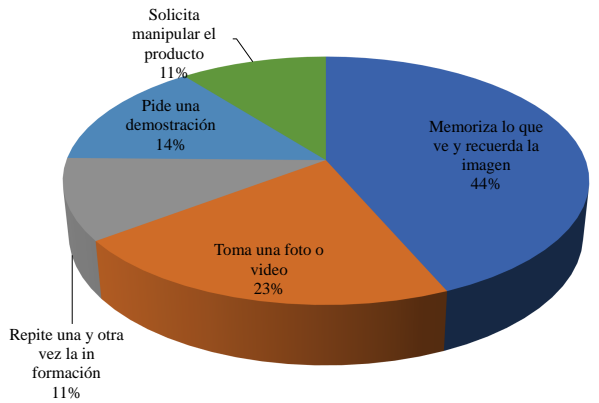

Fuente: Habitantes de la ciudad de Machala de 15 a 70 años
Los factores que influyen en la decisión de compra, reflejado en la figura 3 , indica que el principal factor influyente es la recomendación de otras personas en el $30 \%$, seguido del $21 \%$ de publicidad televisiva, y $19 \%$ de interés personal. En el género masculino el $21 \%$, $17 \%$ y $20 \%$ pertenecen a los factores antes mencionados y en el género femenino el $14 \%, 11 \%$ y $7 \%$ respectivamente. Un dato relevante que influye en la decisión de compra es la exposición a productos/servicios en tiendas o espacios comerciales en el $12 \%$, teniendo un impacto en el $7 \%$ al género masculino y mayoritariamente al género femenino en el $10 \%$.

Figura 3. Influencia al adquirir producto/servicio

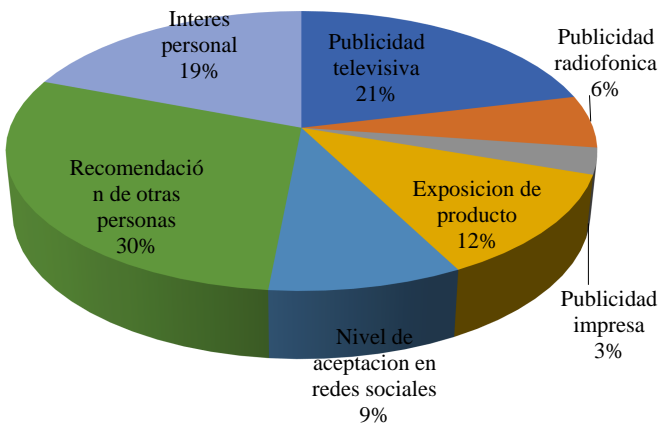

Fuente: Habitantes de la ciudad de Machala de 15 a 70 años

La figura 4 indica que el medio de comunicación más utilizado es el internet con el $41 \%$ de preferencia por jóvenes de entre 20 a 29 años, quienes principalmente son estudiantes. La frecuencia de acceso a este medio es de 4-7 horas al día en el 41\%, 1-3 horas al día el $27 \%$ y más de 10 horas al día el $13 \%$ datos reflejados en la figura 5 .

Figura 4. Medio de comunicación más utilizado

Figura 2. Tipo de publicidad

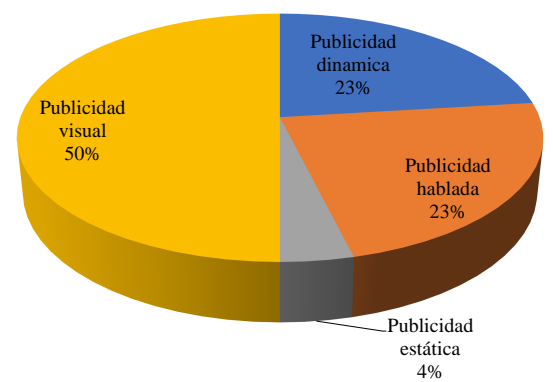

Fuente: Habitantes de la ciudad de Machala de 15 a 70 años

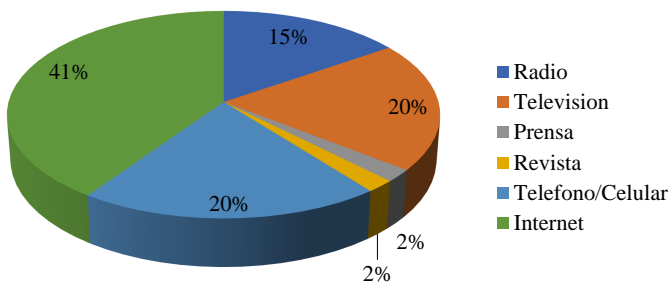

Fuente: Habitantes de la ciudad de Machala de 15 a 70 años 
Figura 5. Frecuencia de acceso a internet

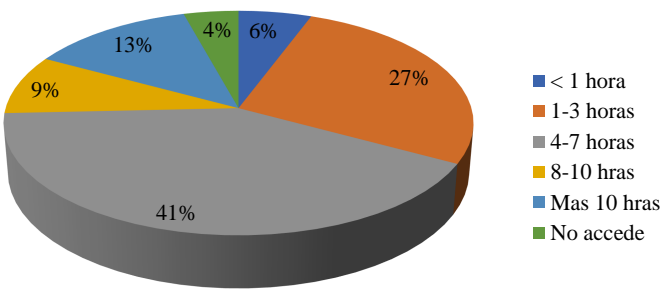

Fuente: Habitantes de la ciudad de Machala de 15 a 70 años

Las redes más utilizadas para obtener información sobre productos y servicios por parte de la población investigada son: Facebook en el 31\%, Instagram con el $19 \%$ y WhatsApp con el $11 \%$. En el Gráfico 6 también indica que el buscador Google es utilizado por el $16 \%$ de los encuestados para mantenerse informado de productos, servicios y empresas, incluyendo también otros medios como son, mensajes de texto, llamadas telefónicas y las exposiciones en el punto de venta.

A través del internet se mantiene informado de diversos productos/ servicios, de los cuales los más destacados son: vestimenta $22 \%$, servicios telefónicos y de paquete $18 \%$, bisutería $14 \%$, artículos de hogar $13 \%$ y cosméticos $9 \%$.

Figura 6. Medio para obtener información

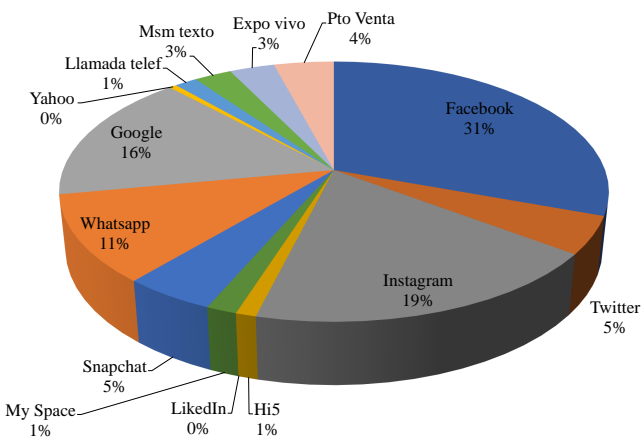

Fuente: Habitantes de la ciudad de Machala de 15 a 70 años

Tal como indica la figura 7 , la televisión es sintonizada por el $59 \%$ de personas de 1 a 3 horas al día por parte de los encuestados, el $20 \%$ lo hace menos de una hora al día y el $17 \%$ de 4 a 7 horas al día. Algunos factores que estimulan la decisión de compra a través de publicidad en TV están expuestos en la Gráfica 8 los cuales son: la marca $25 \%$, precio $18 \%$ y beneficios del producto en el $15 \%$. No obstante otro factor decisivo para la compra a través de publicidad en TV es la promoción con el $13 \%$.
Los productos y servicios adquiridos a través de publicidades en $\mathrm{TV}$ son: alimenticios $28 \%$, bebidas $20 \%$, útiles escolares $18 \%$, cuidado personal $17 \%$, artículos de limpieza y desinfectantes $14 \%$.

Figura 7. Horas de sintonía de TV

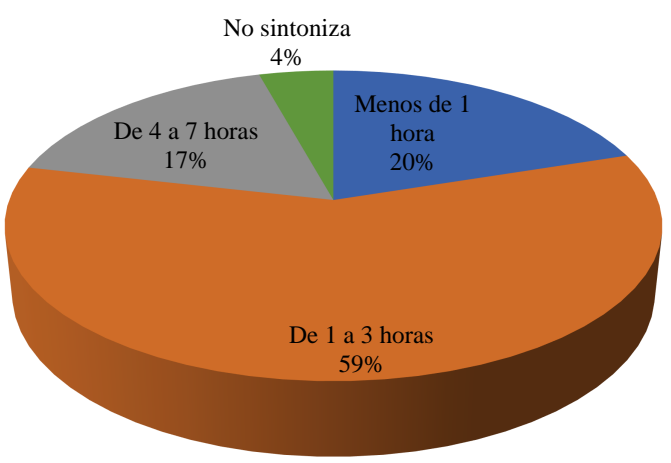

Fuente: Habitantes de la ciudad de Machala de 15 a 70 años

Figura 8. Factores influyentes después de publicidad televisiva

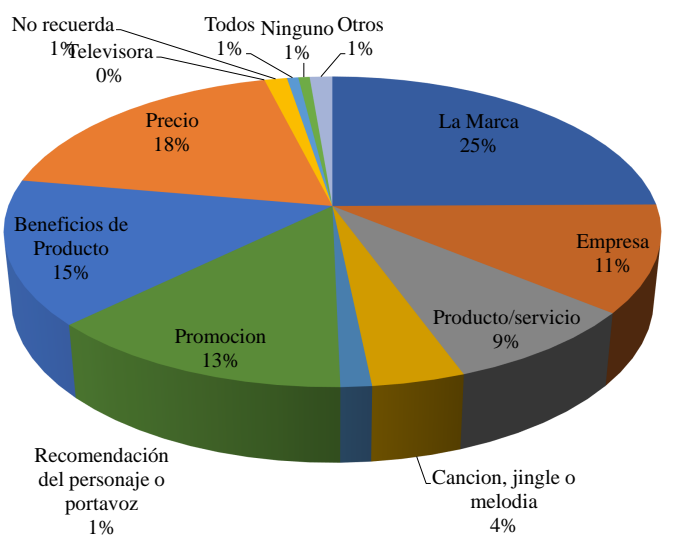

Fuente: Habitantes de la ciudad de Machala de 15 a 70 años

La radio es el medio de comunicación preferido por la muestra poblacional de mayores de 30 años. Como lo indica la figura 9 , el $34 \%$ de encuestados sintoniza la radio de 1-3 horas al día, el $33 \%$ menos de una hora al día, y el $17 \%$ no sintoniza. Los factores que estimula la compra mediante publicidad radiofónica expuestos en la figura 10, son la marca $21 \%$, promociones $15 \%$, beneficios del producto y precio $11 \%$. Los productos y servicios mayormente adquiridos a través de este medio son: servicios telefónicos y de paquete $7 \%$, alimenticios $6 \%$, servicios médicos $6 \%$, y de construcción $5 \%$. 
Figura 9. Horas de sintonía radial

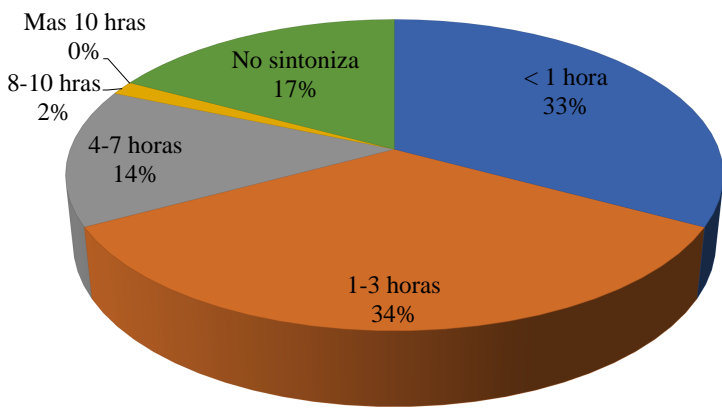

Fuente: Habitantes de la ciudad de Machala de 15 a 70 años

Figura 10. Factores decisivos para comprar mediante radio

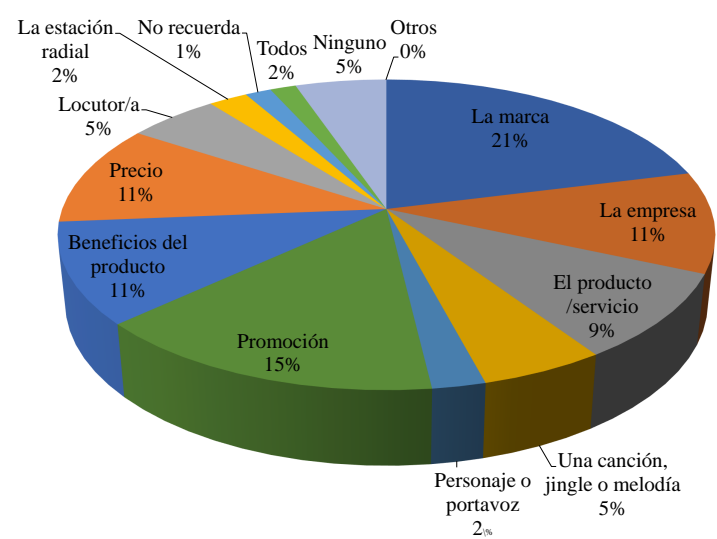

Fuente: Habitantes de la ciudad de Machala de 15 a 70 años

La prensa escrita es el medio utilizado por el $2 \%$ de la población, del cual se observa en la figura 11, el $23 \%$ lo revisa aproximadamente cada mes, otro $23 \%$ nunca lo hace y tan solo el $19 \%$ lo revisa todos los días. Por consiguiente del $19 \%$ que revisa el medio todos los días son personas de un rango de edad superior a 30 años. Este segmento adquiere primordialmente artículos de hogar $6 \%$, fármacos $5 \%, 3 \%$ en productos de cuidado personal, $3 \%$ en útiles escolares y $3 \%$ servicios médicos.

Si bien el uso de revistas es por el $2 \%$ de la población, a través de este medio se decide la compra de cosméticos $17 \%$, vestimenta $15 \%$, bisutería $14 \%$ y cuidado personal $11 \%$.
Figura 11. Frecuencia de lectura de prensa escrita

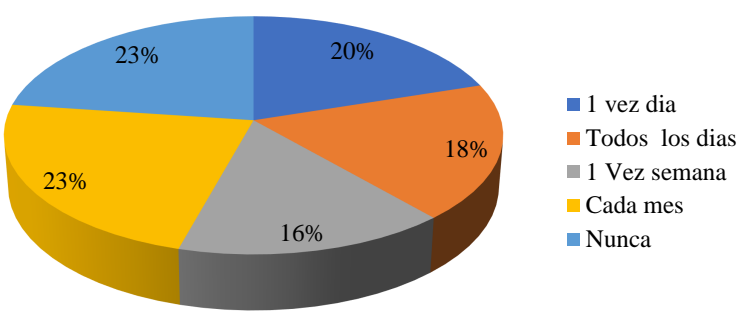

Fuente: Habitantes de la ciudad de Machala de 15 a 70 años

Como indica la figura 12, la población acude al cine tan solo en el $39 \%$ cada 6 meses y el $21 \%$ una vez al año. El segmento está en un rango de edad de 20-35 años. Cabe resaltar que el $22 \%$ de encuestados observan marcas a lo largo de la película y el $21 \%$ destaca el uso de productos propios de marcas utilizados en el desarrollo de la película, datos reflejados en la figura 13 .

De acuerdo a los encuestados, como se observa en la figura 14 , la adquisición de algún tipo de producto o servicio se realiza antes de acudir al cine en el $45 \%$ de los casos y el $28 \%$ en la entrada del cine.

Figura 12. Frecuencia asistencia a cine

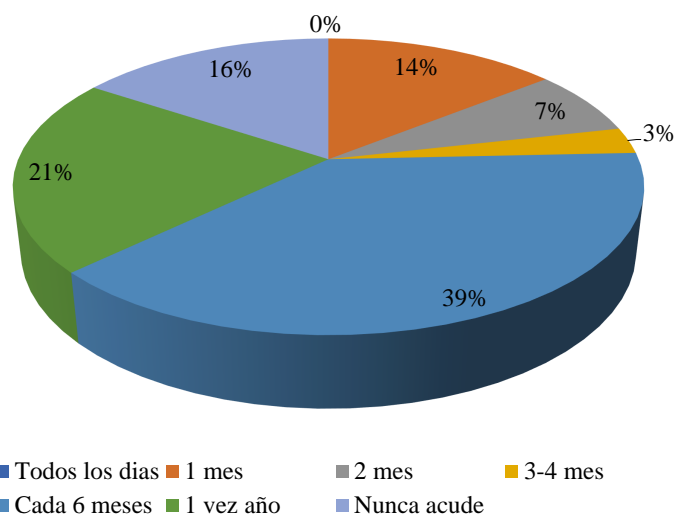

Fuente: Habitantes de la ciudad de Machala de 15 a 70 años 
Figura 13. Aspectos recordativos en el cine

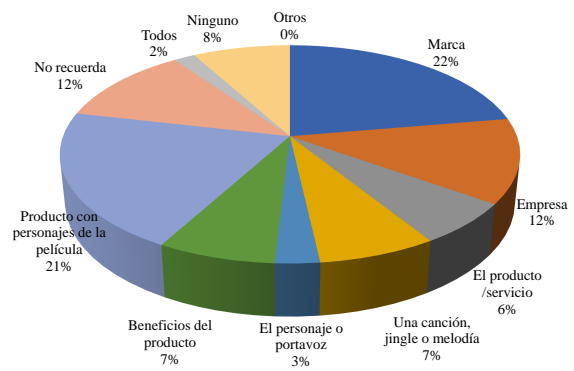

Fuente: Habitantes de la ciudad de Machala de 15 a 70 años

Figura 14. Momento de compra en el cine

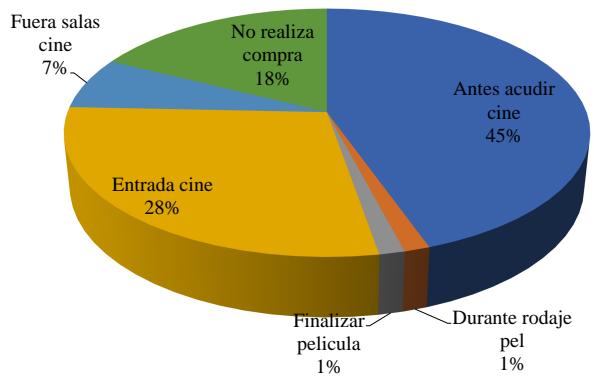

Fuente: Habitantes de la ciudad de Machala de 15 a 70 años

A pesar de que el $57 \%$ de los encuestados no realiza una compra a través de medios de comunicación telefónica y dispositivos móviles, como se observa en la figura 15, el $10 \%$ que si realiza esta actividad, adquiere artículos principalmente de servicios telefónicos y de paquete $12 \%$.

Figura 15. Adquiere productos de dispositivos móviles

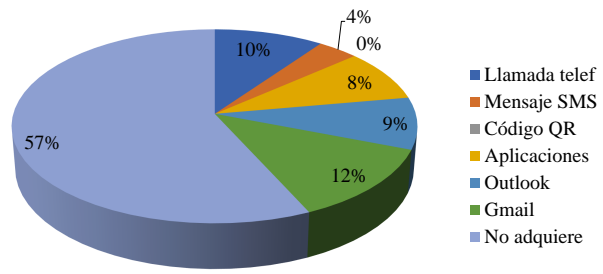

Fuente: Habitantes de la ciudad de Machala de 15 a 70 años

El $77 \%$ de la población investigada indica que la publicidad exterior no causa un gran impacto de compra, a pesar que si observa productos y servicios como: alimentos $29 \%$, bebidas $22 \%$, servicios telefónicos y de paquete $19 \%$ y útiles escolares $15 \%$.

De acuerdo a la figura 16 algunos medios no convencionales generan un gran impacto dentro del punto de venta, el $28 \%$ de encuestados indica que la colocación de los productos en el punto de venta es llamativa y atrayente, el $12 \%$ es mayormente impactado por materiales sonoros o audiovisuales, folletos $15 \%$, islas promocionales $10 \%$, material sonoro y audiovisual $12 \%$. Sin embargo cuando los clientes necesitan ayuda acuden al asistente de ventas un $48 \%$, el $19 \%$ a expositores, y el $12 \%$ a la cajera del almacén.

Figura 16. Publicidad de mayor impacto dentro de un almacén

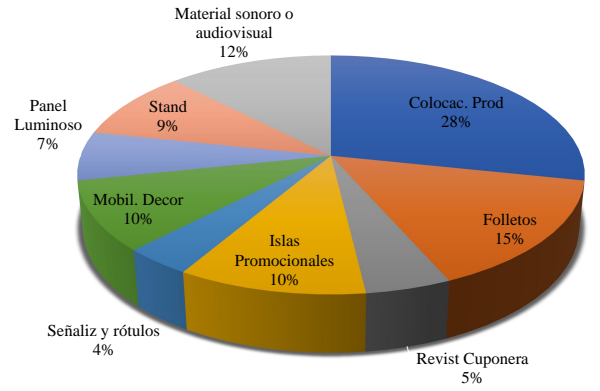

Fuente: Habitantes de la ciudad de Machala de 15 a 70 años

\section{Conclusiones}

Al término de la investigación realizada se concluye que el factor principal que incide en la decisión de compra es la recomendación de terceras personas que puede ser provocado por: un asesor de ventas, familiares o amistades que interfieren en el poder de decisión de compra de algún producto o servicio.

Entre los medios convencionales, el internet es el medio que más utilizado por el $40 \%$ de encuestados. Este medio también interviene en la decisión de compra pues la población está conectado al internet, utilizando blogs, sitios web y redes sociales. Facebook, Instagram y WhatsApp son las redes más eficaces para estar en contacto con el segmento y el buscador de Google es utilizado por el $16 \%$ de los encuestados para informarse de productos, servicios y empresas.

La TV es el medio de comunicación masiva sintonizado por el $20 \%$ del total de encuestados, utilizado para comunicar bienes y servicios, cuya frecuencia de uso es de 1a 3 horas por día el $59 \%$. Los factores que estimulan la decisión de compra a través de publicidades en TV son: la marca, precio, beneficios del producto y la promoción vista a través del medio.

La radio es sintonizado por el $34 \%$ de encuestados cuya frecuencia es de 1 a 3 horas al día. Este medio es preferido por la muestra poblacional de mayores de 30 años y los factores que estimula la compra mediante publicidad radiofónica son la marca, promociones, beneficios del producto y precio.

La prensa escrita es revisada por el $23 \%$ de encuestados cada mes y el $19 \%$ lo hace todos los días, indicando que en nuestra sociedad la preferencia por este medio es del $2 \%$. Los factores que deciden la compra son por factores promocionales y cupones de recorte principalmente. 
La población que acude al cine está en un rango de edades entre 20-35 años, asistiendo en un periodo rotativo de 6 meses. Dicho segmento ha notado la presencia de marcas y el uso de estas en sus productos en el desarrollo de la película.

La publicidad exterior no causa un gran impacto de compra en el entorno. Solo el $23 \%$ de la muestra se siente persuadido por este medio para realizar compras de productos como: alimentos, bebidas, servicios telefónicos y útiles escolares.

Los medios no convencionales en el punto de venta causan un gran impacto que influye en la decisión de la compra. La colocación de productos dentro del almacén estimula la decisión de compra en un $28 \%$, acompañado de folletos $15 \%$, islas promocionales $10 \%$, material sonoro y audiovisual $12 \%$ debido a que puede captar y generar mayores ingresos en la empresa que utilice este tipo de medios como refuerzo de la publicidad en medios masivos. A pesar de que el telemarketing y mailing no se desarrolla con gran auge en nuestro entorno. El $10 \%$ de la población realiza compras a través de medios de comunicación telefónica y móvil para adquirir servicios telefónicos y de paquete.

Por lo tanto, el sistema de representación de la población investigada es principalmente visual, debido a que el $50 \%$ de personas necesita observar y en ocasiones tomar una foto o video para recordar el tipo de publicidad que está visualizando. El género masculino utiliza primordialmente un sistema de representación visual porque memoriza publicidades de tipo visual y dinámica, mientras el femenino recuerda publicidades de tipo visual, dinámica y oral, siendo un indicador para el desarrollo y ejecución de estratégicas comerciales de acuerdo al segmento al que nos dirigimos.

\section{Referencias Bibliográficas}

Cevallos, M., Limonta, R., y Dueñas, F. (2017). Analisis de los servicios publicitarios demandados por las empresas públicas y privadas de la ciudad de Portoviejo. Revista San Gregorio.

Chiavenato, I. (2007). Introducción a la teoría general de la administración. México: McGraw-Hill Interamericana.

Degrado, D. (2005). Televisión, publicidad y comunicación. Comunicar, 1-9.

Española, R. A. (s.f.). Diccionario de la Real Academia Española. Descargado de http: / / dle.rae.es / ? id=UYYKIUK

Galmés-cerezo, M., y Arjona-martín, J. B. (2014). La situación de la publicidad y las comunicaciones de marketing del sector de la salud en España., 5(Imc), 183-194.

Garcia Uoeda, M. (2011). Las claves de la publicidad. Esic Editorial.

Gema, T., Casado, M., y Valladolid, U. D. (2012). El relato audiovisual publicitario del siglo XXI. Del medio televisión al medio internet. ¿Nuevos medios o nuevas formas de consumo audiovisual? Revista Comunicación, 1(10), 164-175.

Kotler, P., y Armstrong, G. (2011). Marketing: Edicion para Latinoamerica. México: Pearson Educación.

Martín-Guart, R., y Fernández Cavia, J. (2014). La publicidad y la agencia de medios frente al cambio en el ecosistema mediatico. Cuadernos.info, 34, 1325. doi: $10.7764 /$ cdi.34.572

Molina, C. M. (2008). La publicidad en Internet: situación actual y tendencias en la comunicación con el consumidor. (Spanish). Interactive Advertising: Current Situation and Tendency on the Communication with the Consumer. (English), 13(24), 183-201. doi: 10 .1016/j.sbspro.2014.08.276

Mondo, T. S., y Costa, J. P. d. (2011). Influencia de la comunicacion del marketing. Estudios y perspectivas en Turismo.

Natalia, P. (2014). Los medios publicitarios en el contexto actual. Revista de estrategias. Tendencias e innovacion en comunicacion. doi: 10.6035/2174-0992.2014 7

Rivera, S., y Rodríguez, C. (2011). Importancia del Comercio Electrónico y las TICs en el Sector Turístico Latinoamericano. , 2-3. doi: 10.13140/RG.2.1.4826 .2807

Rodriguez del Bosque, I., Suárez Vázquez, A., y García de los Salmones, M. d. M. (2008). Dirección publicitaria. Barcelona: UOC Editorial.

Russell, J. T., Lane, W. R., y Whitehill K, K. (2005). Publicidad. México.

Stanton, W. J., Etzel, M. J., y Walker, B. J. (2007). Fundamentos de Marketing. México: McGraw-Hill Interamericana.

Valdiva Garcia, J. A. (2015). Comercialización de productos y servicios en pequeños negocios o microempresas. IC Editorial.

Valencia Medranda, A., Palacios Bauz, I., Cedeño Pinargote, J., Collins Ventura, N., y de Ingeniería en Marketing, C. (2015). Influencia Del Marketing Digital En El Proceso De Decisión De Compra. , 1-5.

Recibido: 30 de junio de 2018 Aceptado: 3 de septiembre de 2018 